ENSAYO

\title{
CLAVES DE LECTURA DEL MAGISTERIO DE JUAN PABLO II
}

\author{
Pedro Morandé
}

El artículo ofrece algunas claves de lectura del magisterio de Juan Pablo II que, a juicio del autor, permiten comprender la continuidad de sus enseñanzas con las del Concilio Vaticano II y la originalidad de su pensamiento. Dio sentido a su pontificado como el gran adviento de la encarnación de Cristo, celebrada el año 2000, y como el inicio de una nueva era cristiana. Más que como una doctrina religiosa o moral, entendió el cristianismo como un acontecimiento, acaecido en el hombre Jesús de Nazaret, en su persona, en la que se

Pedro Morandé. Dr. Phil. en Sociología de la Universidad de Erlangen-Nürnberg, Alemania Federal. Profesor titular de sociología y decano de la Facultad de Ciencias Sociales de la Pontificia Universidad Católica de Chile. Sus áreas de especialización son la Sociología de la Cultura y la Sociología de la Familia. Miembro de la Academia Pontificia de Ciencias Sociales y miembro de número de la Academia de Ciencias Sociales, Políticas y Morales del Instituto de Chile. Entre sus publicaciones pueden mencionarse Synkretismus und offizielles Christentum in Lateinamerika. Ein Beitrag zur Analyse der Beziehung zwischen 'Wort' und 'Ritus' in der nachkolonialen Zeit (München: Fink Verlag, 1982); Cultura y Modernización en América Latina (Pontificia Universidad Católica de Chile, 1984; reeditado por Encuentro Ediciones, Madrid, 1987); Iglesia y Cultura en América Latina (Lima: Editorial VE 1989, 1990); Persona, Matrimonio y Familia (Ediciones Universidad Católica de Chile, 1994); y Familia y Sociedad (Santiago: Editorial Universitaria, 1999). Autor de numerosos artículos vinculados al tema de la familia, la identidad cultural latinoamericana, su ethos barroco, la presencia de la Iglesia en la memoria de los pueblos latinoamericanos, formas de religiosidad y los desafíos culturales que presenta el proceso de modernización en la actual sociedad tecnológica.

Estudios Públicos, 101 (verano 2006). 
manifiesta la plenitud de la divinidad y, con ello, la plenitud de la vocación humana a la comunión en la verdad y en la caridad. El infinito entra en el tiempo. Dios no está fuera de la historia sino en la historia, puesto que este misterio humano-divino se prolonga y se hace contemporáneo a todos los hombres a través de la Iglesia. Esta clave antropológica del cumplimiento de la libertad humana en la comunión de personas resalta el valor inconmensurable de la vida humana, de la familia, de la cultura, del trabajo, de la razón y de la fe, ayudando a formar este conjunto de experiencias lo que muy originalmente llamó "la subjetividad de la sociedad”. Notable fue también cómo aplicó estas enseñanzas a su propia vida y al ejercicio de su ministerio pastoral.

$\mathrm{R}$ hacer una presentación equilibrada del fecundo magisterio de Juan Pablo II durante sus veintiséis años de pontificado, de modo que quisiera limitarme solamente a entregar algunas claves para su lectura, especialmente, aquellas que, en mi modesta opinión, constituyen su mayor originalidad.

\section{La visión de Juan Pablo II sobre su época}

Diferentes analistas de nuestro tiempo suelen hablar de que vivimos un "cambio de época”. A los sociólogos, en general, no nos acomoda mucho esta expresión, puesto que solemos observar procesos de larga duración en que los factores sociales evolucionan con mucha más lentitud que los cambios que perciben las personas en el curso de sus vidas. Es cierto, sin embargo, que la conciencia de nuestra época percibe una transformación social profunda que, aunque estructuralmente se haya iniciado hace varios siglos, se hace hoy más evidente para la experiencia cotidiana, por la masificación de la vida urbana, por el impacto práctico e inmediato del cono- cimiento científico y tecnológico en la vida social, por la emergencia de la C comunicación audiovisual en "tiempo real”, y por un conjunto de otros factores que podríamos resumir señalando que experimentamos un cambio de escala del fenómeno humano que algunos autores describen con la expresión "emergencia de la sociedad mundial”.

Pues bien, el Papa Wojtyla percibió esta conciencia de la época desde muy temprano, en verdad, desde antes de asumir el pontificado, y cuando fue electo, a instancias del cardenal Wyszynski, como él mismo lo reco- 
noce en su testamento ${ }^{1}$, definió la época de su gobierno pastoral como la de un gran adviento, el adviento del tercer milenio, pero también, con mirada teológica, el adviento de Cristo, en la celebración del jubileo del año 2000 y del inicio de un nuevo milenio cristiano. Lo señala expresamente, con intención programática, en su primera encíclica Redemptor Hominis: "Este tiempo en el que ... Dios me ha confiado por misterioso designio el servicio universal vinculado con la Cátedra de San Pedro en Roma, está ya muy cercano al año dos mil. Es difícil decir en estos momentos lo que ese año indicará en el cuadrante de la historia humana y cómo será para cada uno de los pueblos, naciones, países y continentes, por más que ya desde ahora se trate de prever algunos acontecimientos. Para la Iglesia, para el Pueblo de Dios que se ha extendido — aunque de manera desigual— hasta los más lejanos confines de la tierra, aquel año será el año de un gran Jubileo. Nos estamos acercando ya a tal fecha que - aun respetando todas las correcciones debidas a la exactitud cronológica - nos hará recordar y renovar de manera particular la conciencia de la verdad-clave de la fe, expresada por San Juan al principio de su evangelio: 'Y el Verbo se hizo carne y habitó entre nosotros"'?2.

Precisamente porque percibía que la conciencia de la humanidad se sentía atravesando una época de transición, salió a su encuentro contraponiendo la esperanza al temor propio de un tiempo inestable. "No tengáis miedo, abrid las puertas a Cristo” fueron sus primeras palabras como Papa y autorizó la publicación de su libro de respuesta a las preguntas de Vittorio Messori con el sugerente título: Cruzando el Umbral de la Esperanza, que recuerda inmediatamente El Pórtico del Misterio de la Segunda Virtud de Charles Péguy. Simbolizado en el año 2000, su entero pontificado fue visto por él como el cruce de un umbral, litúrgicamente representado por la "puerta santa”, pero que él quería presentar ante todo como un umbral de esperanza fundado en la promesa de Cristo: "estaré con vosotros todos los días, hasta el fin del mundo"3.

Como escribió en su carta apostólica Tertio Millennio Adveniente, preparatoria al jubileo, durante todo el siglo XX fueron manifestándose los hitos del cambio de época que se avecinaba, tanto en los sucesos negativos del siglo, como entre los positivos. De entre estos últimos, el mayor de todos fue, a su juicio, la renovación eclesial introducida por el Concilio

${ }^{1}$ Testamento espiritual de Juan Pablo II publicado en Revista Humanitas $N^{\circ} 38$, Santiago 2005.

2 Juan Pablo II, Redemptor Hominis, n. 1.

${ }^{3}$ Mt. 28, 20. 
Vaticano II. Consideró propiamente este Concilio como el inicio de la nueva época de la Iglesia y fui personalmente testigo de un gesto suyo bastante elocuente, al finalizar la celebración del jubileo de los laicos en noviembre del 2000, última peregrinación masiva del año, de entregar a un representante seglar de cada continente las cuatro Constituciones conciliares, indicándoles no sólo que estaban plenamente vigentes, sino que serían además el punto de referencia seguro para el futuro de la Iglesia. Por ello, puede decirse con toda certeza que Juan Pablo II fue un Papa del Concilio, no sólo porque participó como un destacado protagonista, sino porque todo su magisterio lo entendió como profundización y aplicación pastoral de sus enseñanzas. Me resultan así muy incomprensibles algunos juicios críticos que han intentado contraponer su magisterio y el del Concilio, como si hubiese tenido la intención de detener el "aggiornamento" eclesial. Muy por el contrario, sólo se hace comprensible su magisterio en plena comunión con el Concilio y con el magisterio de los Papas que lo precedieron, no sólo en el sentido genérico de la fidelidad a la tradición de la Iglesia que, en razón de su oficio, todos los Papas practican, sino en el sentido específico de su visión sobre la época histórica que le había tocado vivir y en la que tenía que desarrollar su misión. En varios de los puntos que se describirán enseguida, fue incluso más allá del Concilio.

\section{La antropología cristológica que surge del misterio de la encarnación}

En el centro de su visión del hombre y de la historia puso Juan Pablo II la antropología cristológica y trinitaria, siguiendo los lineamientos de la Constitución conciliar Gaudium et Spes. Todos estamos familiarizados con el hecho de que la frase más recurrentemente usada en su magisterio, es la afirmación antropológica de dicho texto: "El misterio del hombre sólo se esclarece a la luz del misterio del Verbo encarnado"4. Por ello, dedicó su ¿ primera encíclica al redentor del hombre, continuando con la explicación de

@ la misericordia del Padre, su segunda encíclica, y con la acción santificadora del Espíritu Santo, su tercera. En su visión, el cristianismo no es esencialmente una doctrina religiosa o una ética, sino un acontecimiento: en el hombre Jesús de Nazaret se manifestó la plenitud de la vida divina, y por su resurrección de entre los muertos y la acción de su Espíritu continúa presente hasta el fin de los tiempos. Al manifestarse en este hombre la plenitud

${ }^{4}$ Concilio Vaticano II, Constitución pastoral Gaudium et Spes, n. 22. 
de la divinidad, se revela también en él la plenitud de la humanidad, es decir, la vocación para la que Dios creó al hombre desde el principio. Su antropología no surge, en consecuencia, de la especulación filosófica o jurídico política, sino de la contemplación de este acontecimiento que, por gracia divina y no por mérito humano, continúa haciéndose visible en la experiencia de la fe, de la esperanza y de la caridad de la Iglesia.

Personalmente, lo que más me impresionó siempre de Juan Pablo II era la fuerza de su fe viva. Para algunos podría parecer una afirmación trivial, dado que se supone que los Papas, que tienen como misión confirmar la fe de sus hermanos, deberían tenerla. Pero todo cristiano sabe que la fe es una virtud teologal, que no procede del hombre sino de Dios, y que la regala de manera distinta y con diversos grados de profundidad a las personas que se lo solicitan. Cuando esta fe destaca, a los ojos de los demás, por su fuerza, su firmeza, su profundidad o su fidelidad, solemos hablar de ella como de un "carisma”. Juan Pablo II fue, ciertamente, un gran carismático. Veía la presencia del misterio divino allí donde los demás no solemos ver. Si como ha pensado la filosofía desde la imagen de la caverna de Platón en adelante, la paradoja del mirar humano se despliega entre la total oscuridad, donde no se ve, y la total luminosidad, donde tampoco se puede ver porque ciega la vista, podría definirse la fe de las personas que la poseen en abundancia como una luz serena, penetrante, profunda, que ilumina la realidad donde otros no alcanzan a ver por exceso o por falta de luz. Suele decirse, siguiendo la sabiduría popular, que los ojos de una persona son espejo de su alma. Para cualquiera que haya tenido la oportunidad de encontrar personalmente a Juan Pablo II, ésta era una evidencia indesmentible. La profundidad de su mirada traspasaba las personas y las cosas, las volvía trasparentes, es decir, les comunicaba el resplandor de la fe que lo consumía. No era, por tanto, una mirada amenazante, sino serena, paternal, llena de paz, pero con una profundidad que se perdía hacia el infinito.

En lenguaje teológico podría caracterizarse esta forma de mirar desde la profundidad de la fe como una mirada escatológica, es decir, aquella que tiene la capacidad de anticipar al presente, al aquí y ahora de la finitud humana, la plenitud del tiempo, el sentido último de todo. Estremece la razón hasta sus fundamentos, leer uno de los que considero como los más penetrantes textos de su magisterio: "Cuando San Pablo habla del nacimiento del Hijo de Dios lo sitúa en 'la plenitud de los tiempos' (cf. Gal. 4, 4). En realidad el tiempo se ha cumplido por el hecho mismo de que Dios, con la Encarnación, se ha introducido en la historia del hombre. La eternidad ha entrado en el tiempo: ¿qué ‘cumplimiento’ es mayor que éste?, ¿qué otro 
‘cumplimiento’ sería posible?”5 . La fe de Juan Pablo II era la conciencia viva de este cumplimiento de la plenitud de los tiempos en la historia humana, en la historia de cada ser humano. Por ello, había escrito también en su primera encíclica: "Este hombre es el camino de la Iglesia, camino que conduce en cierto modo al origen de todos aquellos caminos por los que debe caminar la Iglesia, porque el hombre — todo hombre sin excepción alguna— ha sido redimido por Cristo, porque con el hombre — cada hombre sin excepción alguna - se ha unido Cristo de algún modo, incluso cuando ese hombre no es consciente de ello, 'Cristo, muerto y resucitado por todos, da siempre al hombre' —a todo hombre y a todos los hombres— '... su luz y su fuerza para que pueda responder a su máxima vocación’”6.

La verdad de la redención es entonces la realización en Cristo de la vocación humana, su cumplimiento. Sin embargo, el conocimiento de este misterio que la fe hace posible no despoja a esta certeza de su propio misterio. Por eso el texto ya citado de Gaudium et Spes habla del esclarecimiento del misterio del hombre en el misterio del Verbo encarnado. La palabra misterio significa también "sacramento", imagen visible de la realidad invisible. San Pablo había hablado de Cristo como imagen de Dios invisible ${ }^{7}$ y Juan Pablo II aplica esta misma categoría a la comprensión del misterio del ser humano redimido. Por ello, afirmará en la catequesis sobre el cuerpo humano que el cuerpo es el sacramento de la persona y en su discurso ante la UNESCO que "hay que considerar íntegramente, y hasta sus últimas consecuencias, al hombre como valor particular y autónomo, como sujeto portador de la trascendencia de la persona. Hay que afirmar al hombre por él mismo, y no por ningún otro motivo o razón: ¡únicamente por él mismo!”». Con la misma mirada defendió apasionadamente la vida humana de los no nacidos y la vida de los enfermos y ancianos hasta su fin natural ${ }^{9}$. Todos estos hermosos textos sobre la dignidad humana del hombre redimido enmudecen, sin embargo, ante lo que enseñó a la Iglesia y al mundo con su propia forma de esperar la muerte, sin ocultar su debilidad y su dolor, su impotencia de no poder hablar y sin renunciar a la misión pastoral que le había sido encomendada y que él la entendió, precisamente, como cumplimiento de su persona. ¿Cómo no recordar las palabras del evangelista, que inicia el relato del cumplimiento de la obra de Cristo, diciendo: “Antes de la

\footnotetext{
${ }^{5}$ Juan Pablo II, Tertio Millennio Adveniente, n. 9.

${ }^{6}$ Juan Pablo II, Redemptor Hominis, n. 14.

${ }^{7}$ Col. 1,15 .

${ }^{8}$ Juan Pablo II, Discurso ante la UNESCO, París, 2 de junio de 1980, n. 10 (el destacado es mío).

${ }^{9}$ Véase Juan Pablo II, Evangelium Vitae.
} 
fiesta de la Pascua, sabiendo Jesús que había llegado su hora para pasar de este mundo al Padre, como había amado a los suyos que estaban en el mundo, los amó hasta el fin”? ${ }^{10}$.

\section{La prioridad antropológica de la familia y de la cultura}

Desde la visión sacramental de la vida humana que surge de su antropología cristológica, destaca con particular fuerza la experiencia de comunión entre los seres humanos a imagen de la comunión trinitaria. Recurrió por ello muchas veces en su magisterio a este hermoso texto conciliar “Cuando Cristo nuestro Señor ruega al Padre que todos sean 'uno' ... como nosotros también somos ‘uno’ (Jn. 17, 21-22), descubre horizontes superiores a la razón humana, porque insinúa una cierta semejanza entre la unión de las personas divinas y la unión de los hijos de Dios en la verdad y en la caridad. Esta semejanza pone de manifiesto cómo el hombre, que es en la tierra la única criatura que Dios ha querido por sí misma, no pueda encontrarse plenamente a sí mismo sino por la sincera entrega de sí mismo”11. El destino comunional de la vida humana ha sido reconocido por los propios obispos ${ }^{12}$ como uno de los núcleos teologales más importantes del Concilio Vaticano II y el pontífice lo aplicó a todos los diversos ámbitos de la convivencia humana. La Iglesia es sacramento de comunión ${ }^{13}$ porque lo es la persona misma, llamada a la comunión con Dios y con los demás seres humanos en la verdad y en la caridad. Por ello escribió: "Dios es amor y vive en sí mismo un misterio de comunión personal de amor. Creándola a su imagen y conservándola continuamente en el ser, Dios inscribe en la humanidad del hombre y de la mujer la vocación y consiguientemente la capacidad y la responsabilidad del amor y de la comunión. El amor es por tanto la vocación fundamental e innata de todo ser humano. En cuanto espíritu encarnado, es decir, alma que se expresa en el cuerpo informado por un espíritu inmortal, el hombre está llamado al amor en esta su totalidad unificada" 14 .

La primera experiencia comunional del ser humano en la que es posible vivir una "íntima comunidad de vida y de amor" es el matrimonio y la

\footnotetext{
${ }^{10} \mathrm{Jn} .13,1$.

${ }^{11}$ Concilio Vaticano II, Constitución pastoral Gaudium et Spes, n. 24.

12 Así ocurrió en el Sínodo Extraordinario dedicado al estudio del Concilio Vaticano II en 1985.

${ }^{13}$ Véase Concilio Vaticano II, Constitución Lumen Gentium, n. 1.

14 Juan Pablo II, Exhortación apostólica Familiaris Consortio, n. 11.
} 
familia ${ }^{15}$. Juan Pablo II dedicó muchas brillantes páginas de su magisterio a este tema, a partir de la enseñanza del propio Jesucristo que, consultado por los fariseos y también por sus discípulos acerca del matrimonio y del repudio del cónyuge, los remite al mismo acto creador de Dios, "al principio"16. Tal remisión a la experiencia originaria la interpretó Juan Pablo II como un indicación no sólo relativa a la institución del matrimonio, sino a la comprensión de la naturaleza humana misma, a la constitutiva diferencia entre varón y mujer que, precisamente en virtud de esa diferencia, están llamados a devenir "una sola carne”, communio personarum. De modo que cuando se habla genéricamente de seres humanos o de personas, no se debe suponer que la diferencia entre varón y mujer es puramente accidental, o socialmente atribuida por terceros, como suele argumentarse hoy en día, sino una determinación antropológica esencial. Como lo ha elaborado teológica y antropológicamente después un grupo de personas agrupadas en el Instituto Juan Pablo II para el estudio del matrimonio y la familia, que recibió del propio pontífice la misión de profundizar este conocimiento, existe una directa relación analógica entre la unidad dual de cuerpo y espíritu, de varón y mujer y de individuo y sociedad ${ }^{17}$ que remite al carácter comunional de la vida humana en su ser “imagen y semejanza” de Dios mismo. Así se comprende mejor también el abundante uso bíblico de imágenes esponsalicias para referirse a la relación entre Dios y su pueblo y la teología de San Pablo que ve en el misterio nupcial un signo de la nueva alianza entre Cristo y la Iglesia $^{18}$.

Ciertamente es éste uno de los rasgos más originales del pensamiento de Juan Pablo II y que toca algunos de los aspectos más confusos de la antropología de nuestra época, que oscila entre un hedonismo despersonalizado y un espiritualismo desencarnado, y cuya consecuencia, en ambos casos, es la instrumentalización de la vida humana con fines individuales o colectivos, dando sustento a ese nihilismo libertino ${ }^{19}$ que no sólo niega teóricamente la dignidad de la persona, sino que pretende arrancarla de la misma experiencia personal. Está también detrás de la indiferencia de los

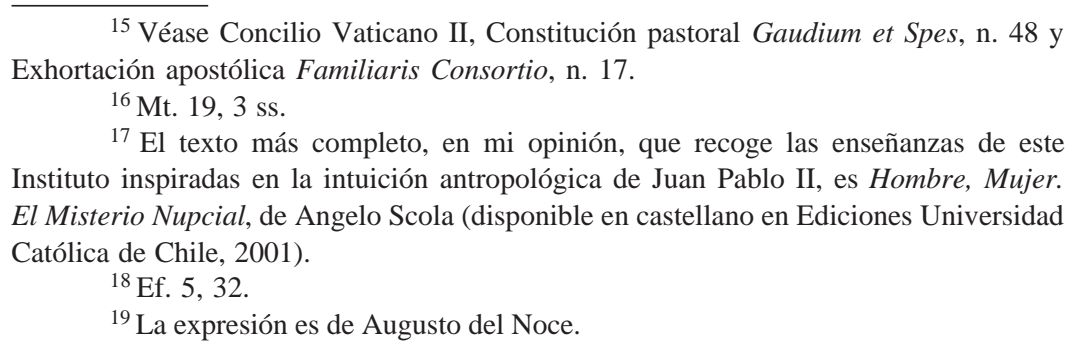


exitosos frente al sufrimiento de los más débiles, como son los pobres, los discapacitados, los ancianos o los niños, despreciados en su corporeidad o en su inteligencia, y, en general, detrás de la negación de la vida humana en su subjetividad corporal y espiritual, sea que se recurra para ello a la violencia o que se valga pasivamente de la indiferencia. Dado el destino comunional de la existencia humana, Juan Pablo II nunca separó la dimensión antropológica de la dimensión social de la vida, como si bastase remitir la primera al ámbito privado y la segunda a la esfera pública. Por el contrario, fue un defensor de la vida humana en todos los ámbitos y en relación al conjunto de todos sus factores, siendo esta defensa su principal criterio de discernimiento en relación a la legitimidad del ordenamiento jurídico y social.

Así, planteó la novedosa idea de que la familia es la primera institución a favor de una auténtica "ecología humana", puesto que en ella "el hombre recibe las primeras nociones sobre la verdad y el bien; aprende qué quiere decir amar y ser amado, y por consiguiente qué quiere decir en concreto ser una persona. Se entiende aquí la familia fundada en el matrimonio, en el que el don recíproco de sí por parte del hombre y de la mujer crea un ambiente de vida en el cual el niño puede nacer y desarrollar sus potencialidades, hacerse consciente de su dignidad y prepararse a afrontar su destino único e irrepetible" ${ }^{20}$. Me parece especialmente interesante que Juan Pablo II haya recurrido a la vinculación entre familia y ecología humana, en primer lugar, porque el fenómeno de la transición demográfica que afecta a todo el mundo, pero muy especial y dramáticamente a Europa, ha mostrado que los incentivos económicos y de orden funcional no han sido capaz de detener, menos aun de revertir, la tendencia a la disminución del número de hijos y al correspondiente envejecimiento de la población. Sin el gusto por la vida que surge de la experiencia de comunión incondicional entre el varón y la mujer que está en la base de la familia, difícilmente se podrá revertir la tendencia, de mediano y largo plazo, de que poblaciones y culturas enteras desaparezcan de la faz de la tierra. En segundo lugar, porque no sólo en la familia ocurre el misterio de la procreación y del venir de los hijos a la existencia, sino que allí aprenden ellos también, por el testimonio y la sabiduría de la educación de los padres y de los demás miembros de la familia, cuál es el sentido de la vocación humana, qué significa amar y ser amado, es decir, ser una persona. Ninguna educación curricular, funcionalmente determinada, por buena que llegase a ser, puede sustituir el vínculo de total gratuidad que se desarrolla entre los padres y sus hijos y que, una vez

${ }^{20}$ Juan Pablo II, Centesimus Annus, n. 39. 
experimentado y aprendido, podrá reproducirse en una nueva generación. Nadie puede saber qué significa la paternidad (maternidad) si no experimenta profundamente también qué significa la filiación. En tercer lugar, porque sale al encuentro de uno de los desafíos más inquietantes de nuestro tiempo, que es la cultura del padre ausente, con sus graves secuelas de infantilización de la población, narcisismo, violencia escolar y juvenil, déficit de autoestima y pérdida del sentido de autoridad, entre otras. Efectivamente, la familia parece representar una experiencia humana esencial para el delicado equilibrio ecológico, es decir, de mediano y largo plazo, que permita la sobrevivencia de la vida humana en el mundo.

La misma originalidad que se percibe en el magisterio de Juan Pablo II sobre el matrimonio y la familia se encuentra también en el ámbito de la cultura. Muchas veces señaló, en referencia a su Polonia natal, que ella pudo mantener la soberanía propia de la tradición y de la historia de un pueblo, ante sucesivas invasiones de potencias extranjeras, gracias a la cultura. De modo análogo a la familia, la cultura sólo se puede entender desde su raíz antropológica. Nadie escoge dónde nacer, qué padres tener, qué lengua hablar21, qué época histórica vivir. Ningún ser humano, cuando viene a la existencia, llega a un mundo despoblado, por hacer o inventar, sino a un mundo humanamente habitado, con sentido, que se ha apropiado de la sabiduría de las generaciones que le han precedido y que se esforzará en transmitir a las generaciones futuras lo que su experiencia e inteligencia haya considerado lo más estimable y valioso. Se suele hablar hoy en día, con lenguaje económico, del "capital social” y del "capital cultural”, y no me parece mal de que se lo haga. Pero como enseñó Juan Pablo II en numerosas ocasiones, la cultura pertenece al ser del hombre antes que a su tener, "la cultura se sitúa siempre en relación esencial y necesaria a lo que el hombre es, mientras que la relación a lo que el hombre tiene, a su 'tener', no sólo es secundaria, sino totalmente relativa. Todo el 'tener' del hombre no es importante para la cultura, ni es factor creador de cultura, sino en la medida en que el hombre, por medio de su 'tener', puede al mismo tiempo 'ser' más plenamente como hombre, llegar a ser más plenamente hombre en todas las dimensiones de su existencia, en todo lo que caracteriza su humanidad”22. Precisamente porque pertenece al ser, es condición de posibilidad y, simultáneamente, máxima expresión de su libertad. Mediante ella “un pue-

${ }^{21}$ Me refiero a la lengua materna, puesto que sólo se pueden aprender otras lenguas en relación y en diálogo con la lengua materna. Ella hunde sus raíces en el inconsciente humano, especialmente, como lengua oral.

22 Juan Pablo II, Discurso ante la UNESCO, París, 2 de junio de 1980, n. 7. 
blo expresa y promueve lo que llamaría su originaria ‘soberanía' espiritual”, señalará ante la $\mathrm{ONU}^{23}$. En la cultura de las naciones se produce ese delicado equilibrio entre la universalidad del valor de la dignidad humana y la forma siempre histórica y particular de vivirla y experimentarla. Por ello, pondrá tantas veces de relieve el valor de la diversidad cultural humana, exhortando a apreciarla como tal, a no tenerle miedo, pero llamando igualmente la atención sobre los derechos humanos universales, individuales tanto como sociales, y a superar todo falso nacionalismo que pretenda la autoafirmación propia a costa del derecho de los otros pueblos a su propia libertad y cultura.

\section{La subjetividad de la sociedad}

La clave antropológica que está en la base del modo como Juan Pablo II observaba la vida humana y la historia contemporánea, lo llevó a acuñar también otra expresión muy original y propia de su magisterio: el concepto de "subjetividad de la sociedad" ${ }^{24}$. Es una expresión que se encuentra en continuidad con el concepto de subsidiariedad, definido por Pío XI en su encíclica Quadragesimo Anno, y que plantea que las diferentes comunidades naturales e intermedias con las que se va formando el tejido social deben ser respetadas en su libertad de iniciativa y protagonismo. Tal principio es inmediatamente comprensible en el plano individual: nadie debería sustituir a otro en el ejercicio de su libertad, puesto que cuando lo hace, lo despoja de su condición de sujeto y lo reduce a un objeto. Lo consideraría como un medio y no como un fin en sí mismo. Pero al pasar del plano individual al social, la aplicación de este principio se vuelve más problemática. La sociedad actual se organiza cada vez más de manera funcional y especializada, lo que quiere decir que no toma en cuenta la totalidad de la persona sino que selecciona sólo aquellos aspectos de su conducta relevantes para la función específica de que se trate. Si a ello se agrega la creciente complejidad de los procedimientos y la variedad de las situaciones, resulta cada vez más difícil que estas comunidades complejas puedan mantener una referencia a la subjetividad, olvidándose que los seres humanos que en ellas trabajan o están asociados tienen la vocación de

${ }^{23}$ Juan Pablo II, Discurso ante la Asamblea de la ONU, Nueva York, 5 de octubre de 1995, n. 8.

${ }^{24}$ La expresión la usó en sus encíclicas Laborem Exercens (n. 14), Sollicitudo Rei Socialis (n. 15) y Centesimus Annus (n. 13). 
ser personas. Cuando ello sucede, tales comunidades $\mathrm{y}$, a veces, hasta sistemas sociales de gran magnitud, pueden conculcar la libertad y el protagonismo de las personas.

Me parece que éste es el contexto en que Juan Pablo II reclama la "subjetividad de la sociedad". De modo particular, se refiere al colapso del socialismo real: "Según la doctrina social de la Iglesia, la socialidad del hombre no se agota en el Estado, sino que se realiza en diversos grupos intermedios, comenzando por la familia y siguiendo por los grupos económicos, sociales, políticos y culturales, los cuales, como provienen de la misma naturaleza humana, tienen su propia autonomía, sin salirse del ámbito del bien común. Es a esto a lo que he llamado 'subjetividad de la sociedad' la cual, junto con la subjetividad del individuo, ha sido anulada por el socialismo real”25. Pero enseguida aclarará que no está pensando sólo en el socialismo real, puesto que la causa última de este abandono de la subjetividad la sitúa en el ateísmo. "Precisamente en la respuesta a la llamada de Dios, implícita en el ser de las cosas, es donde el hombre se hace consciente de su trascendente dignidad. Todo hombre ha de dar esta respuesta, en la que consiste el culmen de su humanidad y que ningún mecanismo social o sujeto colectivo puede sustituir. La negación de Dios priva de su fundamento a la persona y, consiguientemente, la induce a organizar el orden social prescindiendo de la dignidad y responsabilidad de la persona ... El ateísmo del que aquí se habla tiene estrecha relación con el racionalismo iluminista, que concibe la realidad humana y social del hombre de manera mecanicista" 26 . El problema es, por tanto, universal y afecta al modo mismo de organización de la sociedad moderna.

Aunque el concepto de "subjetividad de la sociedad" y el de "subsidiariedad” están estrechamente vinculados, parecería que la expresión introducida por Juan Pablo II pone adicionalmente de relieve dos cosas. En primer lugar, que tal expresión no debería reducirse a la condición de un principio jurídico institucional del ordenamiento social, como frecuentemente se hace con el principio de subsidiariedad, sino que remite más bien a la $\checkmark$ experiencia humana real y efectiva mediante la cual el hombre descubre su dignidad de persona, qué significa amar y ser amado, y cómo tal experiencia - califica y determina sus vínculos interhumanos, como ya se señaló en el caso de la familia y la cultura, pero que debería también considerarse a la hora de analizar el trabajo, la educación, la actividad económica y política, y

\footnotetext{
${ }^{25}$ Juan Pablo II, Centesimus Annus, n. 13.

${ }^{26}$ Juan Pablo II, Centesimus Annus.
} 
todas las restantes actividades humanas. En segundo lugar, que la subjetividad está referida a la prioridad del valor de la vida humana como tal, es decir, de toda vida humana, por ser una vida que tiene la vocación de realizarse como la vida de una persona. Ambos aspectos requieren una explicación adicional.

Desde los inicios de la filosofía moderna se impuso una definición de la subjetividad reducida a la condición del individuo transformado en subjectum, es decir, en fundamento de sí mismo y único lugar de síntesis de lo diverso. Tal condición de sujeto fue aplicable originalmente sólo a Dios. Pero con el correr del tiempo y el desarrollo de la crítica a la tradición cristiana, comienza progresivamente a desplazarse hacia la ficción de un sujeto trascendental, primero, y de un individuo "cualquiera" después. Como contrapartida, el vínculo social pasó a concebirse con las características de un objeto determinado desde la síntesis cognitiva del individuo. Esta visión a la vez presupone y refuerza, como su consecuencia, la incomunicabilidad de la experiencia del yo, puesto que para cumplir con la condición de ser fundamento de sí mismo, este sujeto debe observar y manipular a las cosas y a los demás sujetos como objetos.

Desde la formación fenomenológica del Papa Wojtyla, en cambio, la subjetividad no se define por oposición o diferencia con los objetos, ni en general, desde la dimensión cognitiva. La subjetividad se describe más bien desde la autoconciencia de quien actúa humanamente, asumiendo la responsabilidad por sus propios actos, en el contexto de una experiencia de encuentro e interrelación con otros seres humanos. Es esta experiencia de la responsabilidad sobre los actos asumidos en primera persona la que pone de manifiesto la moralidad consustancial del vivir humano y de su libertad. El punto de referencia de la moralidad no es el individuo autocontenido en sí mismo, que realiza su voluntad para apropiarse o dominar los objetos del mundo, sino la persona, es decir, el sujeto que descubre su vocación al amor, a la communio personarum, como la esencia de su propia dignidad, y que al actuar conforme a ella construye su propia persona, su propia subjetividad. Juan Pablo II recoge frecuentemente la expresión "hacer más humana la vida humana”, usada en Gaudium et Spes para describir la finalidad de la convivencia social. Ella revela todo su sentido precisamente en el contexto de esta autoconciencia de la moralidad de la acción y de su responsabilidad para la convivencia personal, que lleva al sujeto a querer transformar los "actos del hombre" en "actos humanos", es decir, a ponerlos a la altura de la dignidad de su vocación, o por el contrario, a desconocerla o a com- 
portarse indiferentemente frente a ella. En esta elección reside la dramaticidad de la libertad humana.

Tratándose de una experiencia humana elemental, indeducible e irreductible, que sólo se puede vivir vocacionalmente, en primera persona, no se puede afirmar la dignidad humana sin la defensa irrestricta y total de la vida humana misma. "Hay que afirmar al hombre por él mismo, y no por ningún otro motivo o razón”, señalaba en la ya citada alocución en París, añadiendo que se refería al hombre en su totalidad, "en el conjunto integral de su subjetividad espiritual y material”27. Es la misma idea fuerza que desarrolla en su encíclica Evangelium Vitae donde pareciera sugerir que el asesinato de Abel a manos de Caín es el verdadero pecado original de la humanidad ${ }^{28}$. El Dios de Jesucristo es el Dios de la vida, la cual es el regalo más precioso que ha puesto al cuidado del hombre, puesto que su destino es la comunión de amor con Dios mismo. Nadie tiene, pues, derecho a quitarla. Y aunque mantuvo la tradicional enseñanza de la legítima defensa, subrayó que esta defensa debe considerar la proporcionalidad de los medios en relación al agresor injusto, lo que en el contexto del desarrollo tecnológico actual, con su altísimo poder de destrucción, suele volverlos desproporcionados. Por ello se opuso con singular energía a la guerra del Golfo y tampoco aceptó el concepto de guerra preventiva para justificar la invasión de Irak. En el mismo sentido, aunque no condenó la pena de muerte como tal, la consideró, sin embargo, extemporánea, puesto que las condiciones actuales de seguridad de los penales eran suficientes como para garantizar la tranquilidad de la vida social ${ }^{29}$.

Juan Pablo II dedicó la jornada del primero de enero de cada año a analizar la situación internacional desde el punto de vista de sus amenazas a la vida humana y a la convivencia entre los pueblos, proponiendo, en cambio, el camino de la reconciliación, del perdón y de la paz. En enero de 1997, en el mensaje titulado “Ofrece el Perdón, Recibe la Paz”, habló de la necesidad que tiene la humanidad de una constante "purificación de la memoria", no para olvidar el pasado, sino para reconciliarse con él, mirándolo con ojos nuevos desde la perspectiva del amor a Dios y al prójimo. En un gesto notable, que despertó también muchas críticas dentro y fuera de la Iglesia, durante el jubileo del año 2000 y apelando precisamente a la "purificación de la memoria”, pidió solemnemente, arrodillado de cara al crucifijo, perdón

\footnotetext{
${ }^{27}$ Juan Pablo II, Discurso ante la UNESCO, París, 2 de junio de 1980, n 8.

${ }^{28}$ Véase Juan Pablo II, Evangelium Vitae, nn. 40-41.

${ }^{29}$ Véase Juan Pablo II, Evangelium Vitae, nn. 27, 56.
} 
a Dios por todo el daño y la injusticia que los cristianos cometieron a lo largo de la historia. Lo había hecho ya al visitar Auschwitz, al celebrar los 500 años del inicio de la evangelización americana y en el Muro de los lamentos, en su peregrinación a Jerusalén. Pidió también que todas las iglesias particulares hicieran lo propio para la celebración del jubileo. Ni las religiones ni sus seguidores están más allá del mal y de la injusticia. A todos suele gustarnos que los demás pidan perdón, encontrando siempre alguna buena razón para no sentir la necesidad de hacerlo uno mismo. No era esa la calidad humana de Juan Pablo II. Nunca tuvo actitudes moralistas, ni doble estándar. Lo que siempre buscó fue poner la vida humana y su intrínseca vocación al amor como criterio de juicio y discernimiento frente a las costumbres, a las acciones y relaciones sociales, y a las situaciones de hecho que debían ser superadas.

Pues bien, ésta es, según me parece, la idea de la "subjetividad de la sociedad" que tenía el Papa. No tiene relación alguna con el subjetivismo con que habitualmente se asocia hoy día la idea de conciencia. Pero tampoco, con su contrario, es decir, con el objetivismo que pone como medida los resultados alcanzados. Tiene que ver, en cambio, con la libertad humana que permite afirmar que el hombre es la causa de sus actos y, por lo tanto, con la responsabilidad que asume por ellos ante su conciencia y ante las demás personas con quienes está objetivamente vinculado y, en último término, con la sociedad en su conjunto.

\section{El evangelio del trabajo}

Uno de los ámbitos de la vida social donde encontró inmediata aplicación su visión acerca de la prioridad del sujeto humano en razón de su dignidad, fue el del trabajo. El mismo le atribuye el carácter de una clave muy importante, señalando que si ha considerado necesario referirse al trabajo, "no es para recoger y repetir lo que ya se encuentra en las enseñanzas de la Iglesia, sino más bien para poner de relieve —quizá más de lo que se ha hecho hasta ahora - que el trabajo humano es una clave, quizá la clave esencial, de toda la cuestión social, si tratamos de verla verdaderamente desde el punto de vista del bien del hombre"30. No sólo le parecía necesario corregir esa antigua tradición católica, muy presente también en el inconsciente cultural iberoamericano, que vincula el trabajo con la fatiga, con la

${ }^{30}$ Juan Pablo II, Laborem Exercens, n. 3. 
bíblica maldición de tener que ganar el pan con el sudor de la frente al perder el paraíso, sino también y principalmente, la moderna reducción del trabajo a una mercadería o a uno más de los factores productivos. No se trata de que desconociera los aspectos objetivos incluidos en cada una de estas visiones, sino que le preocupaba el trastocamiento de la jerarquía de valores y el desplazamiento del valor de la persona humana de su vértice.

En efecto, el Papa conoció en primera persona la fatiga de trabajar con sus manos en una cantera. Pero no sólo el trabajo físico está sujeto al cansancio. También la educación paulatina de la propia personalidad supone fatigas múltiples y no por ello constituyen una suerte de maldición o de destino fatídico. En la visión bíblica de Juan Pablo II, antes que la fatiga y el sudor de la frente está el mandato divino de "dominar" la tierra y de hacerlo en cuanto "imagen y semejanza” del creador. Que el ser humano sea considerado por el creador como el "señor" de la creación y que lo sea precisamente en cuanto imagen de Dios, es un signo elocuente de la dignidad propia y específica del sujeto humano, que se extiende a todos los dominios de su actividad, pero particularmente también al trabajo, mediante el cual sale al encuentro de las necesidades materiales de sí mismo, de su familia, de sus conciudadanos y de todos los que participan de la compleja red de intercambio de los productos del trabajo, pero sale al encuentro también de su vocación, del cumplimiento y realización de su propia persona. Esta dignidad no podría entenderse nunca como una "resultante" de las fuerzas de producción, de entre las cuales hay una que se denomina "fuerza de trabajo", ni de los productos obtenidos, ni de la productividad. La dignidad del trabajo sólo puede provenir de quien lo realiza, de quien es su sujeto. "El hombre debe someter la tierra, debe dominarla, porque como 'imagen de Dios' es una persona, es decir, un ser subjetivo capaz de obrar de manera programada y racional, capaz de decidir acerca de sí y que tiende a realizarse a sí mismo. Como persona, el hombre es pues sujeto del trabajo. Como persona él trabaja, realiza varias acciones pertenecientes al proceso del trabajo; éstas, independientemente de su contenido objetivo, han de servir todas ellas a la realización de su humanidad, al perfeccionamiento de esa vocación de persona, que tiene en virtud de su misma humanidad”31.

La prioridad de la dimensión subjetiva del trabajo sobre la objetiva, en nada desmerece la adecuada percepción de la dimensión objetiva. El Papa sabe que cada sujeto humano, como ser corporal, vive el apremio de la necesidad, como también las personas que viven de su trabajo. Sabe que el

${ }^{31}$ Juan Pablo II, Laborem Exercens, n. 6. 
trabajo es indispensable para la obtención de los ingresos necesarios para la sobrevivencia de las personas, de las familias y de las naciones. Pero sin la referencia original al valor personal de la actividad humana se confunde la jerarquía objetiva de los valores y queda abierto el camino para la explotación, la injusticia, los conflictos entre capital y trabajo y el odio de clases. Por ello, sigue también de este principio de la subjetividad de la persona, la prioridad del trabajo sobre el capital, lo que fundamenta con dos argumentos: primero, que el trabajador es causa eficiente del trabajo, en cambio, el capital, sólo causa instrumental; y segundo, que el capital no es otra cosa que el trabajo acumulado durante muchas generaciones que han ido poniendo su saber, su originalidad, su cultura al servicio del dominio de la naturaleza y la satisfacción de las necesidades sociales. Recuerda a este respecto, el principio rector que la tradición católica ha reconocido en el destino universal de los bienes, es decir, en el libre acceso de todos los seres humanos a los bienes de la creación, y sólo a partir de este principio tiene sentido el derecho de propiedad para el mejor uso racional de los bienes disponibles en la perspectiva del bien común de todos.

Pienso que la evolución de la sociedad y del proceso de trabajo en los años posteriores a su encíclica sobre el trabajo humano han dado la razón a los énfasis puestos por Juan Pablo II, ya que existe cada vez más conciencia que el trabajo calificado e informado es capaz de agregar valor, lo que exige una formación personal de excelencia, investigación y gestión de la información que serían impensables sin la transformación de la propia persona y de sus virtudes laborales a través del proceso mismo de trabajo. La creación de las máquinas inteligentes lejos de disminuir ha aumentado las exigencias de autopreparación, dominio y control de la calidad de la actividad realizada, haciendo del propio sujeto humano un factor determinante del éxito del proceso de trabajo. También ha crecido la conciencia de que el trabajo tiene una compleja dimensión ecológica, no sólo en relación con la renovación de los recursos naturales, sino también con lo que él propiamente llamó "ecología social del trabajo"32, la que incluye necesariamente una forma de solidaridad intergeneracional que haga sustentable el proceso de trabajo en el mediano y largo plazo, aspecto que se ha vuelto especialmente dramático a partir del cambio en la estructura demográfica de la población y su progresivo envejecimiento. Finalmente, hay más conciencia también del valor del trabajo no remunerado, dentro y fuera de las familias, del papel activo del voluntariado y de la actividad que suele denomi- 
narse como el "tercer sector". Queda sin embargo mucho por hacer en relación a la creación de oportunidades que permitan garantizar a cada persona un empleo digno que le permita desarrollar sus capacidades y talentos personales y que le permita también crear y sostener una familia.

Pero el argumento de Juan Pablo II no se queda exclusivamente en el ámbito de la moral social. Como ya se indicó, su naturaleza es teológica. Como señaló durante su visita a Talcahuano, en donde habló a los trabajadores circunstancialmente en un domingo en que se leía el Evangelio de la resurrección de Lázaro, el sentido del trabajo no se descubre de cara a la muerte sino de cara a la vida, de cara a la resurrección. La tradición benedictina muy tempranamente había descubierto este mismo filón, poniendo la vida monacal bajo el lema "ora et labora", que daba continuidad a la actividad de los oficios humanos y a la celebración del "oficio divino" o liturgia de las horas. La gloria de Dios es la vida del hombre, ha repetido la Iglesia desde la época patrística, pero evidentemente no se trata de cualquier vida, sino de aquella que respeta la dignidad de su condición de persona, es decir, la vida en la verdad y en la caridad que surge de la comunión en el Cristo resucitado. El trabajo humano está llamado a participar activamente de esta realidad, no sólo en el sentido inmediato de que permite satisfacer las necesidades necesarias para permanecer en la vida y crecer sanamente en ella, sino en el sentido más completo de que el sujeto del trabajo se realiza a través de él como persona, desarrolla objetivamente vínculos de solidaridad con todos quienes participan y sostienen la larga cadena de la división nacional e internacional del trabajo, y permite a cada quien, de manera muy concreta y específica, asumir la responsabilidad debida a la vida propia y a la del prójimo. Guardando la necesaria desproporción entre la criatura y el creador, el trabajo asocia al ser humano a la obra creadora de Dios mismo.

\section{Las dos alas del espíritu humano en la contemplación de la verdad}

Una última clave hermenéutica que quisiera destacar del legado intelectual y humano de Juan Pablo II es la íntima unión que tiene la razón y la fe en su visión de la realidad. Ya se mencionó la carismática fuerza de la fe en este hombre. Pero habría que reconocer inmediatamente la sutileza y finura intelectual de su pensamiento para la comprensión de los grandes dilemas que presenta el mundo moderno al entendimiento del ser y del pensar. Pienso sobre todo en la tan ligera y apresuradamente llamada era postmetafísica, del "pensamiento débil”, que renunciando a la búsqueda de 
todo fundamento último, con el pretexto de que desde él podría desarrollarse una posición autoritaria e intolerante, hace sucumbir la reflexión en el océano de las opiniones circunstanciales, fugaces, que se generalizan e imponen en virtud de los medios de comunicación. ¿Pero no se termina de esta manera sustituyendo una tiranía por otra, la supuesta tiranía del filósofo asociada al poder, por la tiranía de quienes producen, gestionan y distribuyen universalmente la información? Me parece que la figura y la obra de este Papa magno es un claro desmentido de los temores postmodernos. Desde la certeza de la fe, que no es otra cosa que la contemplación del misterio presente, la razón no se ve forzada a afirmaciones arbitrarias, sino más bien se ve estimulada a dejarse asombrar por la realidad y a preguntarse constantemente por el conjunto de los factores que están en juego.

¿Qué es lo que une a la razón y la fe en la contemplación de la verdad? El hecho de que la verdad que anuncia el cristianismo no es una doctrina, un conjunto de enunciados, sino un acontecimiento ${ }^{33}$, la vida, muerte y resurrección de una persona, el misterio de esta persona que, en la Iglesia, se hace contemporánea a los hombres de todos los tiempos y a los actualmente vivos. En sus encíclicas Fides et Ratio y Veritatis Splendor Juan Pablo II desarrolla, con una inusual profundidad, tanto la dimensión metafísica como moral que la razón humana puede asumir de cara a este acontecimiento. En ello arriesga la razón humana su propia libertad, no tanto en el sentido de elaborar falsas certezas y sucumbir al error, sino en el sentido aún más decisivo de dejar que vuelva a acontecer en el aquí y ahora del tiempo y del mundo la plenitud de la revelación del misterio presente, que está en el origen de todo lo que existe. Desde este horizonte, la verdad no puede ser reducida a una proposición empíricamente verificable, como lo hacen las ciencias empíricas, o a un enunciado que se somete a la prueba de su coherencia lógica, sino que debe más bien iluminar esa experiencia originaria e indeducible de correspondencia con el Ser que abre la inteligencia de cada ser humano a la comprensión del sentido.

En el plano moral, este camino ya había sido claramente insinuado por el Concilio Vaticano II al definir la conciencia moral en los siguientes términos: "En lo íntimo de su conciencia descubre el hombre siempre la existencia de una ley, que no se da él a sí mismo, pero a la cual está obligado a obedecer, y cuya voz, cuando incesantemente le llama a hacer el bien y evitar el mal, le habla claramente al corazón, siempre que es necesario: Haz

${ }^{33}$ Véase Scola, Angelo: "Libertad Humana y Verdad a Partir de la Encíclica Fides et Ratio”, Humanitas No 15, Santiago 1999, Separata. 
esto, evita aquello ... La conciencia es el núcleo más secreto y el sagrario del hombre, donde él se encuentra a solas con Dios, cuya voz resuena en lo más íntimo de aquél ... Mas el hombre no puede encaminarse hacia el bien sino tan sólo mediante la libertad que tanto ensalzan y con ardor tanto buscan nuestros contemporáneos, y no sin razón. Con frecuencia, sin embargo, la fomentan en forma depravada, como si no fuera más que una licencia que permite hacer cualquier cosa, aunque fuere mala. Al contrario, la verdadera libertad es el signo más alto de la imagen divina en el hombre"34. Juan Pablo II profundiza esta concepción en Veritatis Splendor, presentando con la parábola del joven rico que encuentra a Jesús, la tensión entre la ley, el cumplir los mandamientos, y la plenitud de la vida, que exige pasar del enunciado de la ley al cumplimiento del bien en la propia vida, es decir, dejar que el bien acontezca como bien.

Un razonamiento análogo es el que desarrolla Fides et Ratio. Esta vez, la tensión de la libertad aparece solicitada por los términos "saber" y "sabiduría”. Desde Kant, la metafísica moderna se orientó por su pregunta ¿qué puedo saber?, es decir, por el análisis de las condiciones de posibilidad del saber, de aquello que está presupuesto en el conocimiento de las ciencias y que ellas mismas no lo interrogan. La metafísica se volvió así epistemología. ¿Pero qué sabiduría tiene el saber de este saber, qué aporta al conocimiento del sentido de la existencia y a su realización? Juan Pablo II responde esta cuestión precisamente desde la tradición sapiencial de la Biblia, abierta siempre al sentido último de todo, y desde el cumplimiento de esta verdad como acontecimiento en la encarnación del Verbo, sabiduría de Dios, en la historia humana.

Que el infinito entre en el tiempo y asuma la condición finita humana es, naturalmente, algo que sobrepasa la razón y requiere de la fe, es decir, del hecho de que el misterio mismo quiera revelarse. Dice el Papa: "El Hijo de Dios crucificado es el acontecimiento histórico contra el cual se estrella todo intento de la mente de construir sobre argumentaciones solamente humanas una justificación suficiente del sentido de la existencia. El verdadero punto central, que desafía toda filosofía, es la muerte de Jesucristo en la cruz ... Para lo que Dios quiere llevar a cabo ya no es posible la mera sabiduría del hombre sabio, sino que se requiere dar un paso decisivo para acoger una novedad radical: 'Ha escogido Dios más bien lo necio del mundo para confundir a los sabios ... Lo plebeyo y despreciable del mundo ha escogido Dios; lo que no es, para reducir a la nada lo que es' (1 Co. 1, 27-28)

${ }^{34}$ Concilio Vaticano II, Constitución pastoral Gaudium et Spes, nn 16-17. 
... No es la sabiduría de las palabras, sino la Palabra de la Sabiduría lo que san Pablo pone como criterio de verdad, y a la vez, de salvación”35.

El deseo humano de saber y la revelación de la sabiduría se llaman recíprocamente. Lo más original de Juan Pablo II a este respecto me parece que es el lugar estratégico, por decir así, que él le asigna a la antropología en el pensar metafísico. "La metafísica no se ha de considerar como alternativa a la antropología, ya que la metafísica permite precisamente dar un fundamento al concepto de dignidad de la persona por su condición espiritual. La persona, en particular, es el ámbito privilegiado para el encuentro con el ser y, por tanto, con la reflexión metafísica ... Dondequiera que el hombre descubra una referencia a lo absoluto y a lo trascendente, se le abre un resquicio de la dimensión metafísica de la realidad: en la verdad, en la belleza, en los valores morales, en las demás personas, en el ser mismo y en Dios”36. Puede decirse que el texto sugiere, en cierto sentido, la conveniencia de desarrollar una antropología ontológica que tenga en el centro la calificación de esta experiencia de encuentro con el ser.

Quisiera concluir esta breve exposición de algunas claves de lectura del magisterio de Juan Pablo II señalando que pocas veces en la historia humana es dable encontrar tanta transparencia y coherencia entre la vida de un autor y sus escritos. Hizo lo que enseñó y enseñó lo que hizo, pero sin ponerse jamás como el principal protagonista. Como a todos nos resultó familiar, su figura estaba siempre precedida de la cruz de Cristo, su báculo, en la que se apoyaba para meditar, para escuchar, para recogerse en actitud de adoración del misterio que revela al ser humano la plenitud de su vocación.

\section{REFERENCIAS}

Concilio Vaticano II: Constitución dogmática Lumen Gentium, sobre la Iglesia, 1964.

Concilio Vaticano II: Constitución pastoral Gaudium et Spes, sobre la Iglesia en el mundo actual, 1965.

Juan Pablo II: Testamento espiritual de Juan Pablo II. En Humanitas Nº 38, Santiago, 2005.

Juan Pablo II: Redemptor Hominis, carta encíclica, 1979.

Juan Pablo II: Discurso ante la UNESCO, París, 2 de junio de 1980.

Juan Pablo II: Laborem Exercens, carta encíclica, 1981.

Juan Pablo II: Exhortación apostólica Familiaris Consortio, 1981.

35 Juan Pablo II, Fides et Ratio No 23.

${ }^{36}$ Ibídem, No 83 (el destacado es mío). 
Juan Pablo II: Sollicitudo Rei Socialis, carta encíclica, 1987.

Juan Pablo II: Centesimus Annus, carta encíclica, 1991.

Juan Pablo II: Veritatis Splendor, carta encíclica, 1993.

Juan Pablo II: Cruzando el Umbral de la Esperanza. Plaza Janés Editores, 1994.

Juan Pablo II: Evangelium Vitae, carta encíclica, 1995.

Juan Pablo II: Discurso ante la Asamblea de la ONU, Nueva York, 5 de octubre de 1995.

Juan Pablo II: Fides et Ratio, carta encíclica, 1998.

Juan Pablo II: Tertio Millennio Adveniente, carta apostólica, 2000.

Péguy, Charles: El Pórtico del Misterio de la Segunda Virtud. Encuentro Ediciones, 1999.

Pío XI: Quadragesimo Anno, carta encíclica, 1931.

Scola, Angelo: "Libertad Humana y Verdad a Partir de la Encíclica 'Fides et Ratio' ”. En Humanitas No 15, Santiago, 1999.

Scola, Angelo: “Hombre, Mujer. El Misterio Nupcial”. Santiago: Ediciones Universidad Católica de Chile, 2001. 